Bull. Chem. Soc. Ethiop. 2014, 28(3), 409-414.

ISSN 1011-3924

Printed in Ethiopia

DOI: http://dx.doi.org/10.4314/bcse.v28i3.10

() 2014 Chemical Society of Ethiopia

\title{
SYNTHESIS, CHARACTERIZATION AND CRYSTAL STRUCTURE OF A DIOXOMOLYBDENUM(VI) COMPLEX DERIVED FROM $N$ '-(2-HYDROXY-4- DIETHAYLAMINOBENZYLIDENE)-4-HYDROXYBENZOHYDRAZIDE
}

\author{
Gui-Hua Sheng ${ }^{1}$, Zhong-Lu You ${ }^{2, *}$ and Hai-Liang Zhu ${ }^{1, *}$ \\ ${ }^{1}$ School of Life Sciences, Shandong University of Technology, ZiBo 255049, China \\ ${ }^{2}$ Department of Chemistry and Chemical Engineering, Liaoning Normal University, Dalian \\ 116029, China
}

(Received October 28, 2013; revised July 10, 2014)

\begin{abstract}
Reaction of $\left[\mathrm{MoO}_{2}(\mathrm{acac})_{2}\right]$ (where acac $=$ acetylacetonate) with $N^{\prime}$-(2-hydroxy-4diethaylaminobenzylidene)-4-hydroxybenzohydrazide $\left(\mathrm{H}_{2} \mathrm{~L}\right)$ in methanol afforded a methanol-coordinated mononuclear molybdenum(VI) oxo complex, $\left[\mathrm{MoO}_{2} \mathrm{~L}(\mathrm{MeOH})\right]$. Crystal and molecular structure of the complex were determined by single crystal X-ray diffraction method. The complex was further characterized by elemental analysis and FT-IR spectra. Single crystal X-ray structural studies indicate that the hydrazone ligand coordinates to the $\mathrm{MoO}_{2}$ core through enolate oxygen, phenolate oxygen and azomethine nitrogen. The Mo atom in the complex is in octahedral coordination. Thermal stability of the complex has also been studied.
\end{abstract}

KEY WORDS: Molybdenum complex, Hydrazone ligand, Crystal structure, X-ray diffraction, Thermal property

\section{INTRODUCTION}

Coordination chemistry of molybdenum(VI) has attracted considerable attention due to its biochemical significance [1-3] as well as for the efficient catalytic properties in several organic synthesis procedures [4-7]. Schiff bases are a kind of interesting ligands in coordination chemistry [8-10]. In recent years, a number of molybdenum(VI) complexes with Schiff bases derived from salicylaldehyde and primary amines have been reported [11-15]. Hydrazones, bearing $-\mathrm{C}(\mathrm{O})-\mathrm{NH}-\mathrm{N}=\mathrm{CH}-$ groups, are a kind of special Schiff bases, which are of particular interest in coordination chemistry and biological applications. Molybdenum complexes with hydrazone ligands have been reported to possess interesting antibacterial activities [16] and catalytic properties [6, 17]. However, molybdenum(VI) complexes derived from hydrazone ligands have been much less studied when compared to other types of ligands. In the present work, we report the synthesis and structure of a new dioxomolybdenum(VI) complex, $\left[\mathrm{MoO}_{2} \mathrm{~L}(\mathrm{MeOH})\right]$, where $\mathrm{L}$ is $N^{\prime}$-(2-hydroxy-4-diethaylaminobenzylidene)-4-hydroxybenzohydrazide $\left(\mathrm{H}_{2} \mathrm{~L}\right)$.

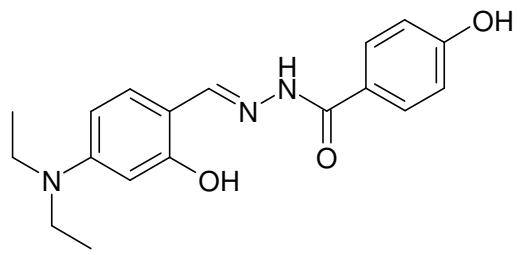

$\mathrm{H}_{2} \mathrm{~L}$

*Corresponding author. E-mail: youzhonglu@Innu.edu.cn, hailiang_zhu@163.com 


\section{EXPERIMENTAL}

\section{Materials and measurements}

Commercially available 2-hydroxy-4-diethylaminobenzaldehyde and 4-hydroxybenzohydrazide were purchased from Aldrich and used without further purification. $\left[\mathrm{MoO}_{2}(\mathrm{acac})_{2}\right]$ was purchased from Aladdin (Shanghai). Other solvents and reagents were made in China and used as obtained. $\mathrm{C}, \mathrm{H}$ and $\mathrm{N}$ elemental analyses were performed with a Perkin-Elmer elemental analyser. Infrared spectra were recorded on a Nicolet AVATAR 360 spectrometer as KBr pellets in the $4000-400 \mathrm{~cm}^{-1}$ region. Thermal stability analysis was performed on a Perkin-Elmer Pyris Diamond TG-DTA thermal analyses system.

\section{Synthesis of $\mathrm{H}_{2} \mathrm{~L}$}

2-Hydroxy-4-diethylaminobenzaldehyde (1.0 mmol, $0.19 \mathrm{~g})$ and 4-hydroxybenzohydrazide (1.0 mmol, $0.15 \mathrm{~g})$ were dissolved in methanol $(30 \mathrm{~mL})$ with stirring. The mixture was stirred for about $30 \mathrm{~min}$ at room temperature to give a colorless solution. The solution was left still in air to slow evaporate of most of the solvent, to give crystalline product of $\mathrm{H}_{2} \mathrm{~L}$. The product was isolated by filtration and washed with cold methanol. Yield, $93 \%$. Analysis: found: $\mathrm{C} 65.8 \%, \mathrm{H}$ $6.5 \%, \mathrm{~N} 13.0 \%$. Calculated for $\mathrm{C}_{18} \mathrm{H}_{21} \mathrm{~N}_{3} \mathrm{O}_{3}: \mathrm{C} 66.0 \%, \mathrm{H} 6.5 \%, \mathrm{~N} 12.8 \%$.

\section{Synthesis of $\left[\mathrm{MoO}_{2} \mathrm{~L}(\mathrm{MeOH})\right]$}

A methanolic solution $(10 \mathrm{~mL})$ of $\left[\mathrm{MoO}_{2}(\mathrm{acac})_{2}\right](0.1 \mathrm{mmol}, 32.6 \mathrm{mg})$ was added to a methanolic solution $(10 \mathrm{~mL})$ of $\mathrm{H}_{2} \mathrm{~L}(0.1 \mathrm{mmol}, 32.7 \mathrm{mg})$ with stirring. The mixture was stirred for $20 \mathrm{~min}$ to give a deep brown solution. The resulting solution was allowed to stand in air for a few days. Brown block-shaped crystals suitable for X-ray single crystal analysis were formed at the bottom of the vessel. The isolated product was washed three times with cold methanol, and dried in a vacuum over anhydrous $\mathrm{CaCl}_{2}$. Yield, 67\%. Analysis: found: $\mathrm{C} 46.9 \%, \mathrm{H} 4.7 \%, \mathrm{~N}$ 8.8\%. Calculated for $\mathrm{C}_{19} \mathrm{H}_{23} \mathrm{MoN}_{3} \mathrm{O}_{6}$ : C 47.0\%, $\mathrm{H} 4.8 \%, \mathrm{~N} 8.7 \%$.

\section{$X$-Ray diffraction}

Diffraction intensities for the complex were collected at 298(2) K using a Bruker D8 VENTURE PHOTON diffractometer with MoK $\alpha$ radiation $(\lambda=0.71073 \AA)$. The collected data were reduced using SAINT [18], and multi-scan absorption corrections were performed using SADABS [19]. The structure was solved by direct method and refined against $F^{2}$ by full-matrix least-squares methods using SHELXTL [20]. All the non-hydrogen atoms were refined anisotropically. The methanol $\mathrm{H}$ atom was located from a difference Fourier map and refined isotropically, with $\mathrm{O}-\mathrm{H}$ distance restrained to $0.85(1) \AA$. The remaining $\mathrm{H}$ atoms were placed in idealized positions and constrained to ride on their parent atoms. The crystallographic data for the complex are summarized in Table 1. Selected bond lengths and angles are given in Table 2.

Table 1. Crystallographic and experimental data for the complex.

\begin{tabular}{|l|l|}
\hline Formula & $\mathrm{C}_{19} \mathrm{H}_{23} \mathrm{MoN}_{3} \mathrm{O}_{6}$ \\
\hline FW & 485.3 \\
\hline Crystal shape/color & block/brown \\
\hline Crystal size/ mm & $0.17 \times 0.17 \times 0.13$ \\
\hline Crystal system & Triclinic \\
\hline Space group & $P-1$ \\
\hline alA & $7.361(2)$ \\
\hline
\end{tabular}

Bull. Chem. Soc. Ethiop. 2014, 28(3) 


\begin{tabular}{|c|c|}
\hline$b / \AA$ & $9.905(2)$ \\
\hline$c / \AA$ & $14.886(2)$ \\
\hline$\alpha{ }^{\rho}$ & $102.141(3)$ \\
\hline$\beta /$ & $100.963(3)$ \\
\hline$\gamma /{ }^{\circ}$ & $106.533(3)$ \\
\hline$V / \AA^{3}$ & $980.3(4)$ \\
\hline$Z$ & 2 \\
\hline$T / \mathrm{K}$ & $298(2)$ \\
\hline$\mu / \mathrm{mm}^{-1}(\mathrm{Mo}-\mathrm{K} \alpha)$ & 0.711 \\
\hline$D_{c} / \mathrm{g} \mathrm{cm}^{-3}$ & 1.644 \\
\hline Reflections/parameters & $3530 / 269$ \\
\hline Independent reflections & 3388 \\
\hline Restraints & 1 \\
\hline Index ranges/ $h, k, l$ & $-8,7 ;-11,11 ;-17,18$ \\
\hline$F(000)$ & 496 \\
\hline $\mathrm{T}_{\min }$ & 0.8886 \\
\hline $\mathrm{T}_{\max }$ & 0.9132 \\
\hline Goodness of fit on $F^{2}$ & 1.133 \\
\hline$R_{1}, w R_{2}[I \geq 2 \sigma(I)]^{\mathrm{a}}$ & $0.0208,0.0543$ \\
\hline$R_{1}, w R_{2}(\text { all data })^{\mathrm{a}}$ & $0.0221,0.0555$ \\
\hline Largest diff. peak and hole/e $\AA^{-3}$ & $0.516,-0.283$ \\
\hline
\end{tabular}

${ }^{\mathrm{a}} \mathrm{R}_{1}=\sum\left\|F_{\mathrm{o}}|-| F_{\mathrm{c}}\right\| / \sum\left|F_{\mathrm{o}}\right|, w \mathrm{R}_{2}=\left[\sum w\left(F_{\mathrm{o}}^{2}-F_{\mathrm{c}}{ }^{2}\right)^{2} / \sum w\left(F_{\mathrm{o}}^{2}\right)^{2}\right]^{1 / 2}$.

Table 2. Selected bond lengths $(\AA)$ and angles $\left(^{\circ}\right)$ for the complex.

\begin{tabular}{|l|l|l|l|}
\hline Mo1-O1 & $1.9200(13)$ & Mo1-O2 & $2.0031(13)$ \\
\hline Mo1-N1 & $2.2008(15)$ & Mo1-O4 & $2.3575(15)$ \\
\hline Mo1-O5 & $1.7096(14)$ & Mo1-O6 & $1.6834(15)$ \\
\hline O6-Mo1-O5 & $105.32(7)$ & O6-Mo1-O1 & $98.70(7)$ \\
\hline O5-Mo1-O1 & $104.40(6)$ & O6-Mo1-O2 & $96.95(7)$ \\
\hline O5-Mo1-O2 & $95.44(6)$ & O1-Mo1-O2 & $150.38(6)$ \\
\hline O6-Mo1-N1 & $96.97(7)$ & O5-Mo1-N1 & $155.39(6)$ \\
\hline O1-Mo1-N1 & $81.98(6)$ & O2-Mo1-N1 & $71.26(5)$ \\
\hline O6-Mo1-O4 & $173.20(6)$ & O5-Mo1-O4 & $80.96(6)$ \\
\hline O1-Mo1-O4 & $81.99(6)$ & O2-Mo1-O4 & $79.64(5)$ \\
\hline N1-Mo1-O4 & $76.39(5)$ & & \\
\hline
\end{tabular}

General

\section{RESULTS AND DISCUSSION}

Replacement of two acetylacetonate ligands in $\left[\mathrm{MoO}_{2}(\mathrm{acac})_{2}\right]$ by hydrazone ligand in methanol resulted in the formation of a methanol-coordinated mononuclear molybdenum(VI) oxo complex. The dinegative ligand is coordinated to the cis- $\mathrm{MoO}_{2}$ core via the phenolate-oxygen, imino-nitrogen, and enolate-oxygen. The sixth coordination site is occupied by the oxygen atom from a methanol solvent. The complex is soluble in methanol, ethanol, and acetonitrile. Molar conductance of the complex at the concentration of $10^{-4} \mathrm{M}$ is $23 \Omega^{-1} \mathrm{~cm}^{2} \mathrm{~mol}^{-1}$, indicating it is a non-electrolyte [21].

\section{Structure description of the complex}

The molecular structure and atom numbering scheme of the complex is shown in Figure 1. The coordination geometry around the Mo atom is highly distorted octahedral. The dianionic hydrazone ligand acts in a planar tridentate manner, forming one five- and one six-membered 
chelate rings with the Mo atom. The hydrazone ligand in the complex is bonded to the $\mathrm{MoO}_{2}$ core in a planar fashion, coordinating through the phenolate $\mathrm{O}$, imino $\mathrm{N}$, and enolate $\mathrm{O}$, and an oxo group lying trans to the nitrogen donor. An ethanol molecule completes the distorted octahedral coordination sphere which lies trans to the other oxo group. The Mo-O(methanol) bond is significantly longer than the other Mo-O bonds, indicating that the methanol molecule is weakly bonded to the $\mathrm{MoO}_{2}$ core and this position holds the possibility of functioning as a substrate binding site.

The atoms $\mathrm{O}(1), \mathrm{O}(5), \mathrm{O}(2)$, and $\mathrm{N}(1)$ of the complex that define a plane show high degree of planarity, the Mo atoms are displaced by 0.331(1) $\AA$ towarding the axial oxo group. The $\mathrm{Mo}=\mathrm{O}$ bond in the complex is within previously reported ranges $[6,17,22,23]$. The angular distortion in the octahedral environment around Mo comes from the five- and six-membered chelate rings taken by the hydrazone ligand. For the same reason, the trans angles significantly deviate from the ideal values of $180^{\circ}$. The hydrazone ligand in the complex is approximately planar, with the benzene rings making a dihedral angle of 5.3(2) ${ }^{\circ}$.

In the crystal structure of the complex (Figure 2), adjacent two molecules are linked by methanol molecules through two intermolecular $\mathrm{O} 4-\mathrm{H} 4 \cdots \mathrm{N} 2$ hydrogen bonds $[\mathrm{O} 4-\mathrm{H} 4=0.85(1)$ $\AA, \mathrm{H} 4 \cdots \mathrm{N} 2^{\mathrm{i}}=1.92(1) \AA, \mathrm{O} 4 \cdots \mathrm{N} 2^{\mathrm{i}}=2.752(2) \AA, \mathrm{O} 4-\mathrm{H} 4 \cdots \mathrm{N} 2^{\mathrm{i}}=172(3)^{\circ}$; symmetry code for $\mathrm{i}: 2$ $-x, 1-y, 1-z]$, to form dimers. The dimers are further linked through intermolecular O3$\mathrm{H} 3 \cdots \mathrm{O} 5$ hydrogen bonds $\left[\mathrm{O} 3-\mathrm{H} 3=0.82 \AA, \mathrm{H} 3 \cdots \mathrm{O}^{\mathrm{ii}}=1.97(1) \AA \mathrm{O}^{\mathrm{O}} 3 \cdots \mathrm{O} 5^{\mathrm{ii}}=2.786(2) \AA\right.$, O3$\mathrm{H} 3 \cdots \mathrm{O} 5^{\mathrm{ii}}=172(3)^{\mathrm{o}}$; symmetry code for ii: $\left.2-x, 2-y, 1-z\right]$, to form chains along the $b$ axis.

Table 3. Parameters between the planes for the complex.

\begin{tabular}{|c|c|c|c|c|c|c|}
\hline$C g$ & $\begin{array}{c}\text { Distance between } \\
\text { ring centroids }(\AA)\end{array}$ & $\begin{array}{c}\text { Dihedral } \\
\text { angle }\left({ }^{\circ}\right)\end{array}$ & $\begin{array}{c}\text { Perpendicular distance } \\
\text { of } C g(\mathrm{I}) \text { on } C g(\mathrm{~J})(\AA)\end{array}$ & $\begin{array}{c}\text { Beta } \\
\text { angle }\left({ }^{\circ}\right)\end{array}$ & $\begin{array}{c}\text { Gamma } \\
\text { angle }\left(^{\circ}\right)\end{array}$ & $\begin{array}{c}\text { Perpendicular } \\
\text { distance of } C g(\mathrm{~J}) \text { on } \\
C g(\mathrm{I})(\AA)\end{array}$ \\
\hline$C g 1-C g 1^{1}$ & 4.461 & 0.02 & 3.280 & 42.68 & 42.68 & 3.280 \\
\hline$C g 1-C g 2^{\text {iii }}$ & 4.864 & 14.22 & 2.917 & 39.21 & 53.15 & 3.769 \\
\hline$C g 3-C g 2^{\text {i11 }}$ & 4.729 & 4.83 & 3.475 & 44.64 & 42.71 & 3.365 \\
\hline$C g 3-C g 2^{1}$ & 3.745 & 4.83 & 3.575 & 17.04 & 17.32 & 3.580 \\
\hline
\end{tabular}

Symmetry codes: iii: $1-x, 1-y, 1-z . C g 1, C g 2$ and $C g 3$ are the centroids of Mo1-O2-C8-N2-N1, C9-C14 and C1-C6 benzene rings.

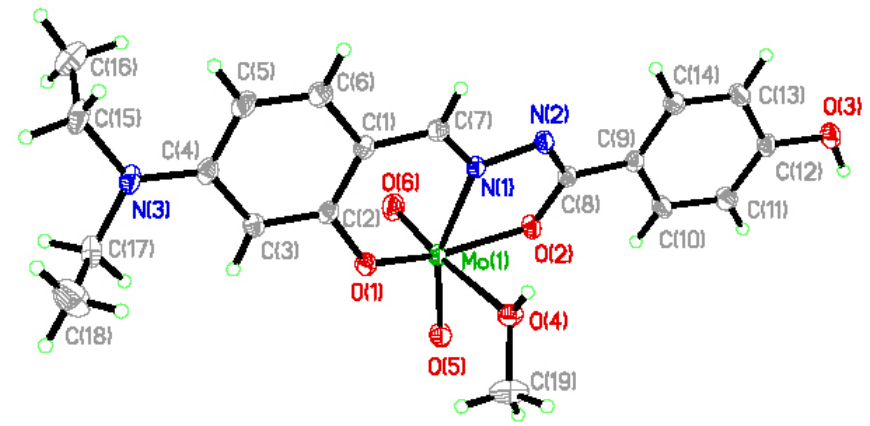

Figure 1. Molecular structure of the complex at $30 \%$ probability displacement.

\section{IR spectra}

The hydrazone ligands showed stretching bands attributed to $\mathrm{C}=\mathrm{O}, \mathrm{C}=\mathrm{N}, \mathrm{C}-\mathrm{OH}$ and $\mathrm{NH}$ at 1656, 1637, 1155 and 1237 , and $3211 \mathrm{~cm}^{-1}$, respectively [24]. The complex exhibits two bands at 892 and $935 \mathrm{~cm}^{-1}$, assigned to symmetric and asymmetric vibrations respectively, of the cis$\mathrm{MoO}_{2}$ core [25]. The bands due to $v_{\mathrm{C}=\mathrm{O}}$ and $v_{\mathrm{NH}}$ were absent in the complex, but new $\mathrm{C}-\mathrm{O}$ stretch appeared at $1249 \mathrm{~cm}^{-1}$. This suggests occurrence of keto-imine tautomerization of the 
ligand during complexation [26]. The $v_{\mathrm{C}=\mathrm{N}}$ absorption observed at $1633 \mathrm{~cm}^{-1}$ in the free hydrazone ligand shifted to $1617 \mathrm{~cm}^{-1}$ upon coordination to the Mo atom [26]. The short peaks in the low wave numbers in the region $450-800 \mathrm{~cm}^{-1}$ may be attributed to Mo-O and Mo-N bonds of the complex.

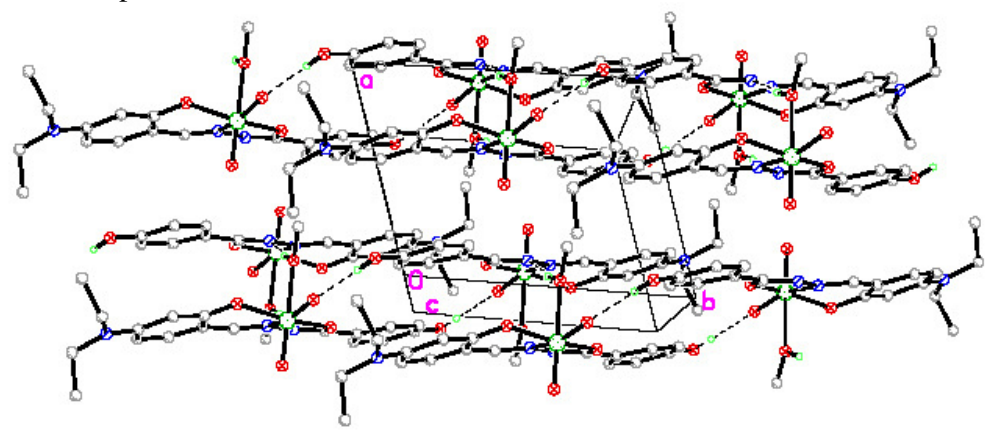

Figure 2. Molecular packing of the complex. Hydrogen bonds are drawn as dashed lines. Hydrogen atoms not related to hydrogen bonds are omitted for clarity.

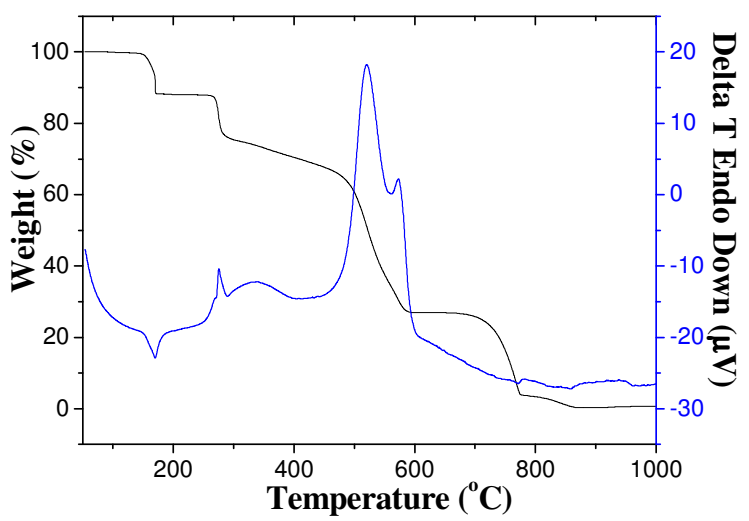

Figure 3. DT-TGA curve of the complex.

\section{Thermal property}

Differential thermal (DT) and thermal gravimetric analyses (TGA) were conducted to examine the stability of the complex (Figure 3). There are several stages of decomposition, but it is very difficult to ascribe them. The complex first decomposed from $143{ }^{\circ} \mathrm{C}$ and ended at $598{ }^{\circ} \mathrm{C}$, corresponding to the loss of the organic groups and the formation of $\mathrm{MoO}_{3}$. The observed weight loss of $28.3 \%$ is close to the calculated value of $29.6 \% . \mathrm{MoO}_{3}$ was then evaporated from $678{ }^{\circ} \mathrm{C}$ to $855^{\circ} \mathrm{C}$.

\section{CONCLUSION}

In summary, a new methanol-coordinated mononuclear dioxomolybdenum(VI) complex derived from $N^{\prime}$-(2-hydroxy-4-diethaylaminobenzylidene)-4-hydroxybenzohydrazide has been prepared and structurally characterized by single crystal X-ray diffraction method, as well as elemental analysis and FT-IR spectroscopic technique. The hydrazone ligand coordinates to the $\mathrm{MoO}_{2}$ core 
through the enolate oxygen, phenolate oxygen and azomethine nitrogen. Thermal stability of the complex has also been studied.

Supplementary data. The crystallographic data for the structure has been deposited with the Cambridge Crystallographic Data Centre (CCDC 968894). Copies of the data can be obtained free of charge on application to the Director, CCDC, 12 Union Road, Cambridge CB2 1EZ, UK (e-mail for deposition: deposit@ccdc.cam.ac.uk).

\section{REFERENCES}

1. Katsaros, N.; Katsarou, M.; Sovilj, S.P.; Babic-Samardzija, K.; Mitic, D.M. Bioinorg. Chem. Appl. 2004, 2, 193.

2. Karaliota, A.; Kamariotaki, M.; Hadjipanajioti, D.; Aletras, V. J. Inorg. Biochem. 1998, 69, 79.

3. Liimatainen, J.; Lehtonen, A.; Sillanpaa, R. Polyhedron 2000, 19, 1133.

4. Rao, S.N.; Munshi, K.N.; Rao, N.N.; Bhadbhade, M.M.; Suresh, E. Polyhedron 1999, 18, 2491.

5. Dinda, R.; Ghosh, S.; Falvello, L.R.; Tomas, M.; Mak, T.C.W. Polyhedron 2006, 25, 2375.

6. Bagherzadeh, M.; Amini, M.; Parastar, H.; Jalali-Heravi, M.; Ellern, A.; Woo, L.K. Inorg. Chem. Commun. 2012, 20, 86.

7. Dinda, R.; Sengupta, P.; Ghosh, S.; Mayer-Figge, H.; Sheldrick, W.S. J. Chem. Soc., Dalton Trans. 2002, 23, 4434.

8. Vafazadeh, R.; Gorji, A.; Ansari, S.; Willis, A.C. Acta Chim. Slov. 2012, 59, 897.

9. Vafazadeh, R.; Bidaki, S. Acta Chim. Slov. 2010, 57, 310.

10. Demir, I.; Bayrakci, M.; Mutlu, K.; Pekacar, A.I. Acta Chim. Slov. 2008, 55, 120.

11. Judmaier, M.E.; Holzer, C.; Volpe, M.; Mosch-Zanetti, N.C. Inorg. Chem. 2012, 51, 9956.

12. Zhao, J.; Zhou, X.; Santos, A.M.; Herdtweck, E.; Romao, C.C.; Kuhn, F.E. Dalton Trans. 2003, 19, 3736

13. Lyashenko, G.; Saischek, G.; Judmaier, M.E.; Volpe, M.; Baumgartner, J.; Belaj, F.; Jancik, V.; Herbst-Irmer, R.; Mosch-Zanetti, N.C. Dalton Trans. 2009, 29, 5655.

14. Vrdoljak, V.; Prugovecki, B.; Matkovic-Calogovic, D.; Hrenar, T.; Dreos, R.; Siega, P. Cryst. Growth Des. 2013, 13, 3773.

15. Vrdoljak, V.; Prugovecki, B.; Matkovic-Calogovic, D.; Dreos, R.; Siega, P.; Tavagnacco, C. Cryst. Growth Des. 2010, 10, 1373.

16. Pasayat, S.; Dash, S.P. Saswati, Majhi, P.K.; Patil, Y.P.; Nethaji, M.; Dash, H.R.; Das, S.; Dinda, R. Polyhedron 2012, 38, 198.

17. Rao, S.N.; Kathale, N.; Rao, N.N.; Munshi, K.N. Inorg. Chim. Acta 2007, 360, 4010.

18. Bruker, SMART and SAINT. Bruker AXS Inc., Madison, Wisconsin, USA, 2002.

19. Sheldrick, G.M. SADABS, Program for Empirical Absorption Correction of Area Detector, University of Göttingen: Germany; 1996.

20. Sheldrick, G.M. Acta Crystallogr. 2008, A64, 112.

21. Geary, W.J. Coord. Chem. Rev. 1971, 7, 81.

22. Vrdoljak, V.; Prugovecki, B.; Matkovic-Calogovic, D.; Pisk, J.; Dreos, R.; Siega, P. Cryst. Growth. Des. 2011, 11, 1244.

23. Debel, R.; Buchholz, A.; Plass, W. Z. Anorg. Allg. Chem. 2008, 634, 2291.

24. Podyachev, S.N.; Litvinov, I.A.; Shagidullin, R.R.; Buzykin, B.I.; Bauer, I.; Osyanina, D.V.; Avvakumova, L.V.; Sudakova, S.N.; Habicher, W.D.; Konovalov, A.I. Spectrohicm. Acta A 2007, 66, 250.

25. Vrdoljak, V.; Prugovečki, B.; Matković-Čalogović, D.; Pisk, J.; Dreos, R.; Siega, P. Cryst. Growth Des. 2011, 11, 1244.

26. Rao, S.N.; Munshi, K.N.; Rao, N.N.; Bhadbhade, M.M.; Suresh, E. Polyhedron 1999, 18, 2491. 